\title{
Spatio-temporal patterns and movement analysis of pigs from smallholder farms and implications for African swine fever spread, Limpopo province, South Africa
}

\author{
Authors: \\ Folorunso O. Fasina ${ }^{1}$ \\ Japhta M. Mokoele ${ }^{1,2}$ \\ B. Tom Spencer ${ }^{1}$ \\ Leo A.M.L. van Leengoed ${ }^{1,3}$ \\ Yvette Bevis ${ }^{4}$ \\ Ingrid Booysen ${ }^{4}$

\begin{abstract}
Affiliations:
${ }^{1}$ Department of Production Pretoria, South Africa
\end{abstract} \\ Animal Studies, University of \\ ${ }^{2}$ Limpopo Department of \\ Agriculture, Groblersdal, \\ South Africa \\ ${ }^{3}$ Department of Farm Animal \\ Medicine, Utrecht University, \\ the Netherlands \\ ${ }^{4}$ Centre for Geoinformation \\ Science, Department of \\ Geography, Geoinformatics \\ and Meteorology, University \\ of Pretoria, South Africa
}

\section{Correspondence to:}

Folorunso Fasina

Email:

dayo.fasina@up.ac.za

\section{Postal address:}

Private Bag X04,

Onderstepoort 0110, South Africa

\section{Dates:}

Received: 24 June 2014

Accepted: 28 Aug. 2015

Published: 27 Nov. 2015

\section{Read online:}

Infectious and zoonotic disease outbreaks have been linked to increasing volumes of legal and illegal trade. Spatio-temporal and trade network analyses have been used to evaluate the risks associated with these challenges elsewhere, but few details are available for the pig sector in South Africa. Regarding pig diseases, Limpopo province is important as the greater part of the province falls within the African swine fever control area. Emerging small-scale pig farmers in Limpopo perceived pig production as an important means of improving their livelihood and an alternative investment. They engage in trading and marketing their products with a potential risk to animal health, because the preferred markets often facilitate potential longdistance spread and disease dispersal over broad geographic areas. In this study, we explored the interconnectedness of smallholder pig farmers in Limpopo, determined the weaknesses and critical control points, and projected interventions that policy makers can implement to reduce the risks to pig health. The geo-coordinates of surveyed farms were used to draw maps, links and networks. Predictive risks to pigs were determined through the analyses of trade networks, and the relationship to previous outbreaks of African swine fever was postulated. Auction points were identified as high-risk areas for the spread of animal diseases. Veterinary authorities should prioritise focused surveillance and diagnostic efforts in Limpopo. Early disease detection and prompt eradication should be targeted and messages promoting enhanced biosecurity to smallholder farmers are advocated. The system may also benefit from the restructuring of marketing and auction networks. Since geographic factors and networks can rapidly facilitate pig disease dispersal over large areas, a multi-disciplinary approach to understanding the complexities that exist around the animal disease epidemiology becomes mandatory.

\section{Introduction}

Infectious and zoonotic diseases outbreaks have intensified in past decades through more intense interconnectedness, rapid transport, the opening-up of borders and increasing volumes of legal and illegal trades (Jones et al. 2013; Perry, Grace \& Sones 2013). Spatio-temporal analyses have been used in veterinary medicine and other fields in recent times (Jiang, Ediger \& Bader 2009; Paul \& Dasgupta 2012; Rivas et al. 2012). Specifically, geographic factors such as roads, water bodies, distances from other outbreaks and markets, among other factors, have been found to play important roles in disease transmission (Food and Agriculture Organization of the United Nations [FAO] 2013; Jori et al. 2009; Korennoy et al. 2014; Pastrana et al. 2014; Rivas et al. 2010, 2012; Sánchez-Vizcaíno, Mur \& Mártinez-López 2012). In addition, trade practices have played major roles in the spread of infectious diseases among livestock (Fournié et al. 2013; McCarron et al. 2015).

Limpopo province is very important in the epidemiology of some transboundary animal diseases in South Africa. In particular, the province has been designated as a control zone for African swine fever together with certain areas of the North West and Mpumalanga provinces (Department of Agriculture, Fisheries and Forestry [DAFF] n.d.; Penrith 2013). Furthermore, the province provides an active domestic animal-wildlife-human interface, making it an ideal location for One Health studies involving zoonoses or disease interactions between wildlife and domestic animals.

Pig production systems and the particular contributions of the emerging small-scale pig farms (ESSPF) in the Limpopo have been described recently (Mokoele et al. 2014). However, the presence of a deeprooted dual market structure remains a major challenge facing small-scale pig producers in the province (Antwi \& Seahlodi 2011). While the commercial pig farmers use the formal markets

How to cite this article: Fasina, F.O., Mokoele, J.M., Spencer, B.T., Van Leengoed, L.A.M.L., Bevis, Y. \& Booysen, I., 2015, 'Spatio-temporal patterns and movement analysis of pigs from smallholder farms and implications for African swine fever spread, Limpopo province, South Africa', Onderstepoort Journal of Veterinary Research 82(1), Art. \#795, 11 pages. http://dx.doi.org/10.4102/ojvr.v82i1.795

Copyright: ( 2015. The Authors. Licensee: AOSIS OpenJournals. This work is licensed under the Creative Commons Attribution License. 
(standard abattoirs, processing plants and supermarkets), the ESSPF farmers can access only the informal markets (local auctions, backyard slaughter, pension sale points and local abattoirs/slaughter slabs).

The most popular auction point and abattoir used by the ESSPFs from Limpopo are Belfast (Mpumalanga) and Bronkhorstspruit (Gauteng) respectively. These locations, which are outside the province, present the ESSPFs with better marketing opportunities and higher incomes for their products. While the commercial interests of the ESSPFs are being secured through these more affluent markets, breach of biosecurity remains evident and the risk of introducing infectious pathogens to non-endemic areas remains high, with imminent threats to the pig industry nationally. MartínezLópez, Pérez and Sánchez-Vizcaíno (2009) and Lindström et al. (2009) have previously identified such risks elsewhere.

ASF is a severe, highly transmissible viral infection of domestic pigs that manifests itself as a haemorrhagic fever, which can cause mortality of up to $100 \%$ in domestic pigs with consequent devastating effects on the livelihoods of farmers who depend on pig production (Bastos, Fasina \& King 2014; de Glanville et al. 2014; Fasina et al. 2012a; Penrith 2013). To date, three types of epidemiological cycle have been described for ASF in southern Africa (Penrith, Thomson \& Bastos 2004).

\section{Historical perspective on the disease in South Africa with emphasis on Limpopo}

The first documented outbreak of ASF in South Africa was recorded in 1928 and this was related to contact between wild pigs and domestic pigs (Penrith 2013; Penrith \& Vosloo 2009). Between 1933 and 1939, historical outbreaks of swine fever were documented (De Kock, Robinson \& Keppel 1940); cases may have been classical or African swine fever, as no clear distinction was established between the two diseases in earlier years (Penrith 2013). Since 1939, South Africa has experienced only sporadic outbreaks that have been limited to the ASF-controlled zones of Limpopo and the Kruger National Park (Boshoff et al. 2007). Although parts of the North West province are designated within the control zones, ASF had not been reported there (DAFF 2014, Table 1). Recent events have, however, proved that the virus, although contained, has the capacity to spread rapidly from the controlled areas to new locations within South Africa (Table 1).
In South Africa between 1993 and 2012, 1309 cases of ASF were documented between 1993 and 2012 from 71 outbreaks in South Africa (Table 1; DAFF 2014). Limpopo has accounted for $76.1 \%$ of all outbreaks to date and the majority of outbreaks from other provinces have links with Limpopo (Table 1).

In September-October 2011, Mpumalanga and Gauteng experienced the first outbreak of ASF to occur outside the control area in recent times. Briefly, some pigs died in a small piggery within the ASF control area in Lephalale (Ellisras), Limpopo with the subsequent sale of surviving pigs at an auction in Sundra, Mpumalanga, and their transportation to Rietpoort abattoir in Gauteng. By January 2012, a total of 172 farms including some 10374 pigs have had primary or secondary contacts with the index farm and only the prompt and co-ordinated intervention of the meat inspectors, private and government veterinarians, the industry and the laboratory (Transboundary Animal Diseases Programme (TADP)) curtailed the outbreaks and eradicated the infections (Evans 2012; Spencer 2012; Spencer \& Penrith 2014).

In this study, we used the spatio-temporal data of locations, possible interactions and marketing structures practised by the emerging small-scale farming communities in Limpopo to draw a network of ESSPF, conduct some spatio-temporal analyses and integrate the outcomes with historical and recent reports of ASF outbreaks in South Africa to map the probable risk, spread and consequences of ASF. In addition, because Limpopo has played a significant role in the outbreaks and dissemination of ASF in South Africa and the province has been declared an ASF-endemic location, we used ASF as a model for a rapidly spreading transboundary animal disease amongst pig populations.

\section{Materials and methods Data collection}

As part of the questionnaire survey conducted for a study on the production systems and dynamics of the ESSPF in Limpopo (Mokoele et al. 2014), the geo-coordinates of all the surveyed ESSPF were obtained using the Garmin $\mathrm{Nuvi}^{\circledR}$ or the Nokia Lumia $635^{\circledR}$ and entered into a Microsoft Excel ${ }^{\circledR}$ spreadsheet. Briefly, Limpopo consists of five districts, namely Sekhukhune, Capricorn, Waterberg, Vhembe and Mopani. A purposive sampling method was

TABLE 1: Reported outbreaks of ASF, 1993-2012 in South Africa.

\begin{tabular}{|c|c|c|c|c|c|c|c|c|c|}
\hline \multirow[t]{2}{*}{ Timeline } & \multirow[t]{2}{*}{ Years } & \multirow[t]{2}{*}{ Province } & \multicolumn{2}{|c|}{ Outbreaks } & \multicolumn{2}{|c|}{ Cases } & \multicolumn{2}{|c|}{ Dead/euthanased } & \multirow[t]{2}{*}{ References } \\
\hline & & & $n$ & $\%$ & $n$ & $\%$ & $n$ & $\%$ & \\
\hline \multirow[t]{5}{*}{ Recent } & $1993-2012$ & Limpopo & 54 & 76.1 & 1040 & 79.4 & 1258 & 64.1 & \multirow{5}{*}{$\begin{array}{l}\text { Evans (2012), Spencer } \\
\text { (2012), Penrith } \\
\text { and Vosloo (2009), } \\
\text { Spencer (2012) and } \\
\text { DAFF (2014) }\end{array}$} \\
\hline & & Mpumalanga & 9 & 12.7 & 133 & 10.2 & 585 & 29.8 & \\
\hline & & Gauteng & 6 & 8.4 & 132 & 10.1 & 116 & 5.9 & \\
\hline & & Kruger National Park & 2 & 2.8 & 4 & 0.3 & 4 & 0.2 & \\
\hline & & National & 71 & - & 1309 & - & 1963 & - & \\
\hline
\end{tabular}

Note: Please see the full reference list of the article, Fasina, F.O., Mokoele, J.M., Spencer, B.T., Van Leengoed, L.A.M.L., Bevis, Y. \& Booysen, I., 2015, 'Spatio-temporal patterns and movement analysis of pigs from smallholder farms and implications for African swine fever spread, Limpopo province, South Africa', Onderstepoort Journal of Veterinary Research $82(1)$, Art. \#795, 11 pages. http:// dx.doi.org/10.4102/ojvr.v82i1.795, for more information. 
targeted at all the available ESSPF farmers $(n=185)$ in these districts.

An original list of 85 small-scale pig farmers was produced by the Limpopo Department of Agriculture but an additional 100 farms that fall within this category but were not listed were recruited into the survey because the preliminary evidence from the field suggested that there were many unlisted ESSPF in the province. The inclusion criterion for the present study was pig farms with $\leq 50$ sows, located within the five districts of Limpopo that have been active in pig production for at least one year (Mokoele et al. 2014). A participatory research model approach was used to collect information from the farmers (Raman, Sanghi \& Chambers 1989).

Of the 185 ESSPFs sent questionnaires, a total of 164 (88.65\%) participated fully and filled in the questionnaires completely. All the data were entered into Microsoft Excel ${ }^{\circledR}$ and checked for consistency, correctness and validity. A preliminary map was drawn to check that all the places surveyed fell within the correct locations within Limpopo, based on the data obtained.
Data were formatted to meet the need for cartography software in ESRI's ArcGIS/ArcView, the R and the NodeXL software and exported appropriately. Extracts of the reports on the ASF outbreaks to date in South Africa were integrated into the final social network maps in order to predict the risk of ASF and advise on intervention strategies.

\section{Data analyses}

\section{Cartography, point mapping and one-way linkages}

ESRI's ArcGIS 10.1 software was used to add into the GIS all the specified geographic co-ordinates of the ESSPF farmers as $\mathrm{XY}$ co-ordinate data. The resulting event layer was then displayed as a point symbol (red dot) portraying the locations of the small-scale pig farmers on an administrative map of Limpopo (Figure 1, Census 2011). Additional fields were added to the initial attribute table of the feature to enable the selection of farms by their designated abattoir. Thereafter the ' $X Y$ to Line' feature tool was used to construct geodetic lines or linkages (Figures $2 \mathrm{a}$ and $2 \mathrm{~b}$ ) representing the shortest distance between the farm and the destination point (the abattoir or auction point). Pig farmers who used local slaughtering points within

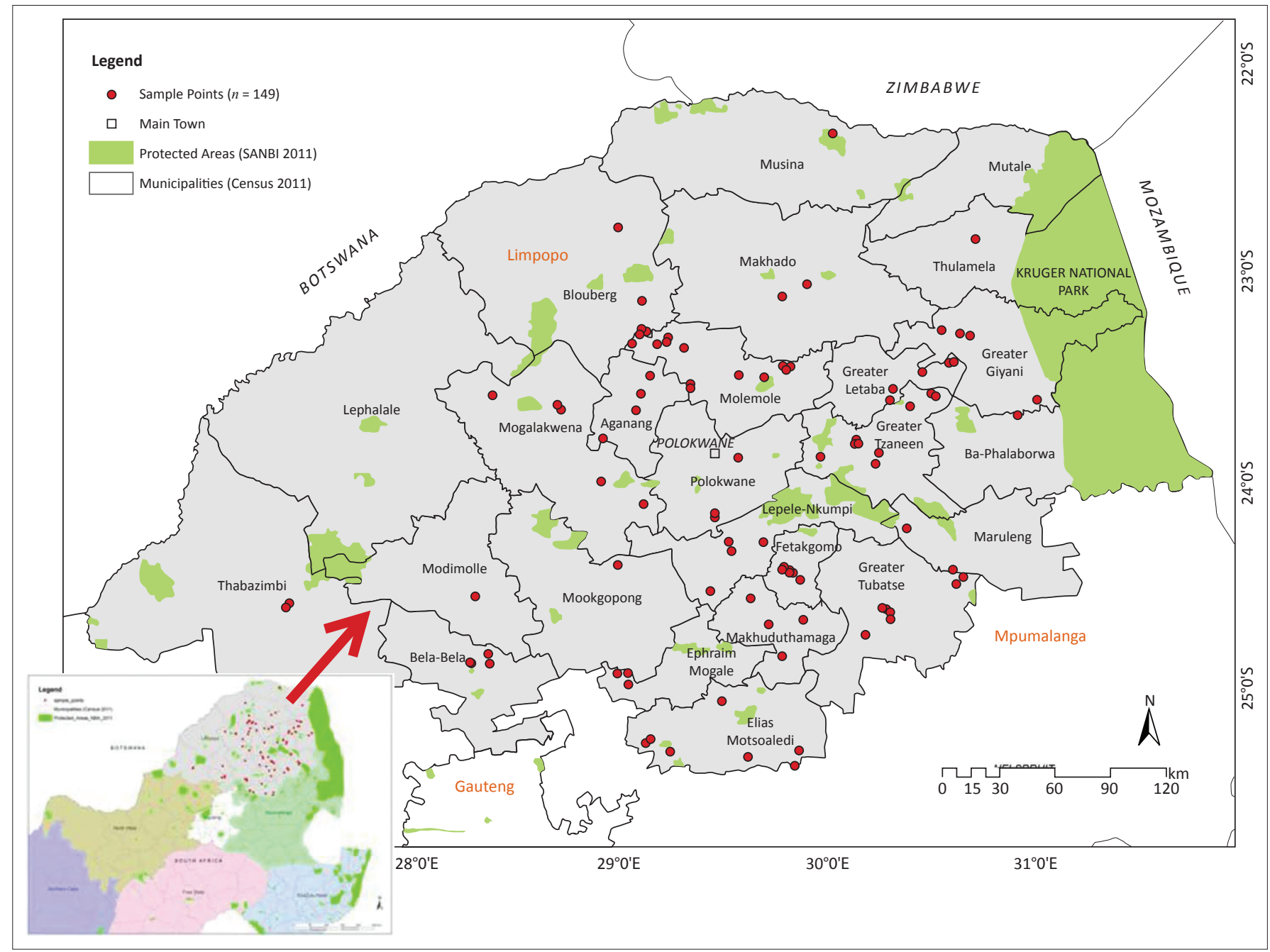

Source: Yvette Bevis and Ingrid Booysen, Geography, Geoinformatics and Meteorology, University of Pretoria

Note: The smaller map indicates Limpopo with contiguous provinces of North West, Gauteng and Mpumalanga, and some other provinces (northern Cape, Free State and KwaZulu-Natal). The call-out map clearly indicates the districts within Limpopo and the spread of the sampled sites.

FIGURE 1: Map of surveyed Limpopo province and locations for emerging small-scale pig farmers in Limpopo, 2012. 
their localities were represented by symbols (red dots) on these two maps. In addition, layers of the primary and secondary road networks within Limpopo and contiguous provinces were made on the map previously generated (Figure 3).

\section{Social network analyses}

Unidirectional networks: Firstly, filtered data were imported from the open Microsoft Excel ${ }^{\circledR}$ workbook into the NodeXL environment and manipulated appropriately for analyses based on the software manufacturer's instructions (NodeXL version 1.0.1.326, Connected Action). Unidirectional graphs with 28 vertices were produced. The graph's vertices were grouped by cluster using the Clauset-Newman-Moore cluster algorithm and laid out using the Harel-Koren Fast Multiscale layout algorithm. The edge colours, widths and opacity were based on edge weight values. The vertex sizes were based on betweenness centrality (BC) values. For emphasis, a graph or network is a set of vertices and edges connected together $[\mathrm{G}=(\mathrm{V}, \mathrm{E})]$, edge $[\mathrm{E}]$ is an association linking two vertices, and vertices [V] are points or locations joined by edges (Jiang et al. 2009).
Multidirectional graphs: In the second instance, data were exported into the $\mathrm{R}$ software environment and mapped for in-going (in-degrees) and out-going (out-degrees) contacts using the modified method of Nøremark and Widgren (2015). Multidirectional graphs were produced separately for indegree and out-degree links. In addition, the k-cores (strength of contribution of each vertex in the total network) were produced based on the number of links that influence each vertex.

\section{Results}

\section{Farm characteristics and trade relationship}

A total of 164 ESSPF were categorised based on the number of sow units (SU) as follows: $1-10 \mathrm{SU}(n=124$; median $=4$, $\left.\mathrm{CI}_{95 \%}=4-5\right) ; 11-20 \mathrm{SU}\left(n=17 ;\right.$ median $\left.=15, \mathrm{CI}_{95 \%}=13-16\right)$; $21-30 \mathrm{SU}\left(n=7 ;\right.$ median $\left.=26, \mathrm{CI}_{95 \%}=23-29\right) ; 31-40 \mathrm{SU}(n$ $=2$; median $\left.=38, \mathrm{CI}_{95 \%}=6-69\right) ; 41-50 \mathrm{SU}(n=1 ;$ median $=$ not applicable, $\mathrm{CI}_{95 \%}=$ not applicable). An abattoir was the preferred slaughter point for the majority of respondents $(105 / 164 ; 64 \%)$ and the abattoir of choice for the ESSPF from

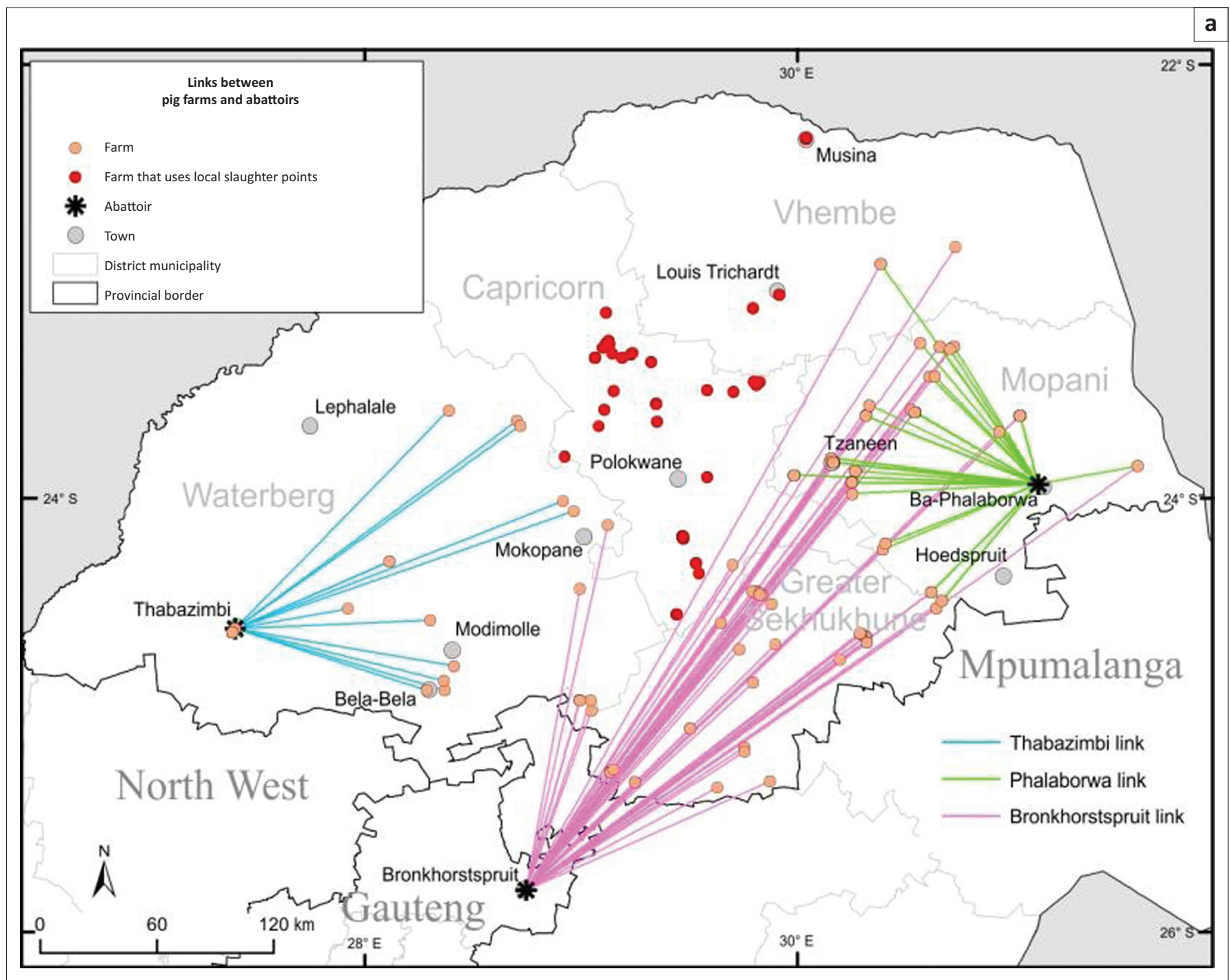

Source: Yvette Bevis and Ingrid Booysen, Geography, Geoinformatics and Meteorology, University of Pretoria

FIGURE 2: (a) Unidirectional links between ESSPF and destinations of final products. (b) Unidirectional links between ESSPF and preferred auction points. 


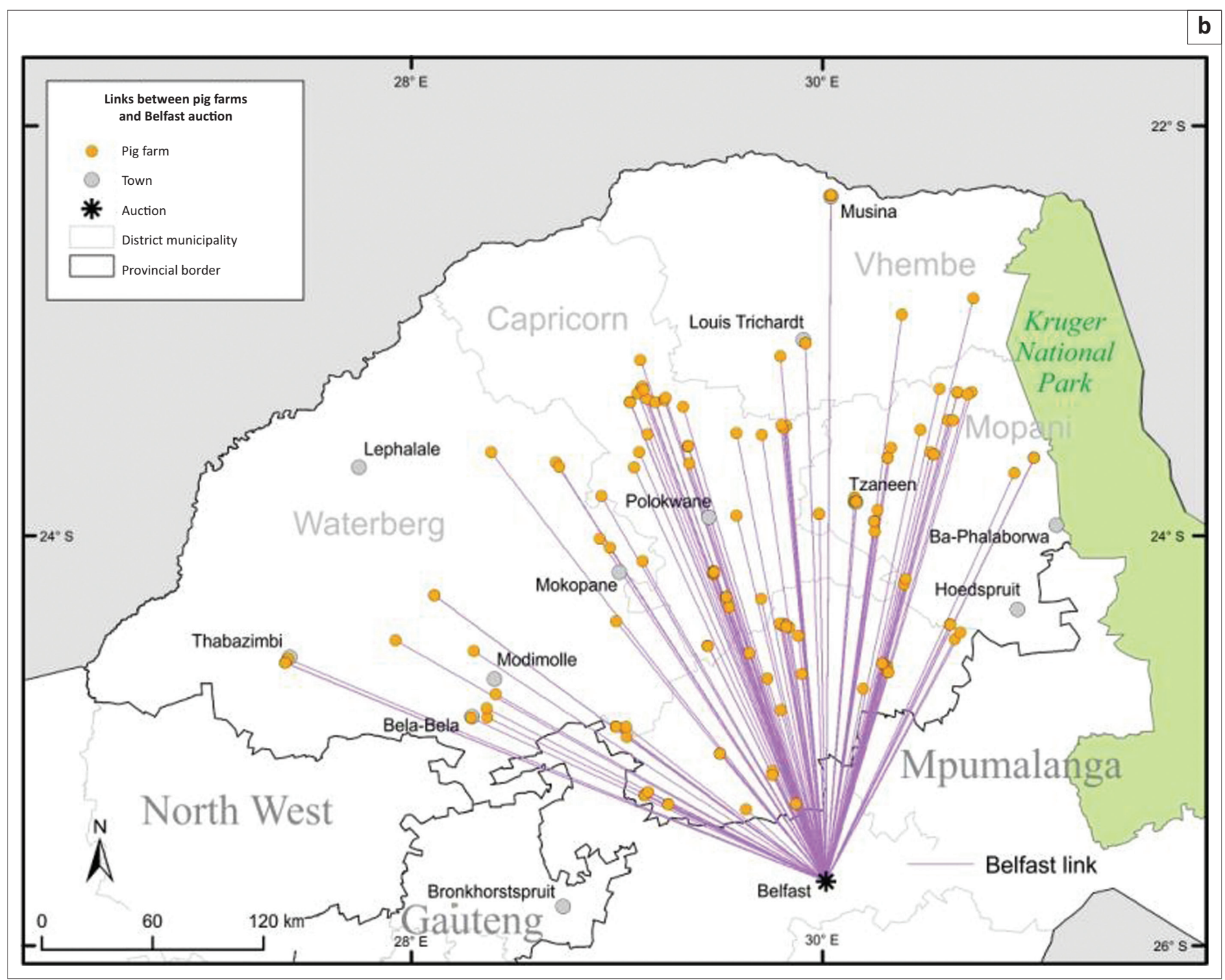

Source: Yvette Bevis and Ingrid Booysen, Geography, Geoinformatics and Meteorology, University of Pretoria

FIGURE 2 (Continues...): (a) Unidirectional links between ESSPF and destinations of final products. (b) Unidirectional links between ESSPF and preferred auction points.

Limpopo was Bronkhorstspruit in Gauteng (55.9\%) and Phalaborwa (26.2\%) and Thabazimbi (10.4\%), both located in Limpopo. A total of $97.6 \%$ of the surveyed ESSPF preferably chose the Belfast auction in Mpumalanga to source their pigs or sell whole animals (Figures 2a and 2b). Importantly, some ESSPFs (34.1\%), especially those from Capricorn district prefer to slaughter pigs within the communities or at pension points (Figures 2a and 2b). Up to 306 pigs were marketed monthly (mean/month $=283$ ) by the surveyed farmers and a total of 3396 pigs were sold in the year 2011 preceding the survey.

The ESSPFs were randomly dispersed throughout Limpopo, with a tendency for greater farm concentrations around Capricorn, Mopani and Greater Sekhukhune districts (Figure 1). However, no specific pattern exists for the farm distributions or choice of slaughter or sale facility and for the distances from the closest national or secondary road(s) to the farms (Table 2; Figure 3).

The average distances between each of the slaughter or sale locations and the nearest national or secondary road networks are shown in Table 2. In addition, the distance covered to travel with the animals to the Belfast auction may be as short as $50 \mathrm{~km}$ up to a distance of about $400 \mathrm{~km}$. The distances travelled to get to local abattoirs or slaughter points were within $5 \mathrm{~km}$ for local slaughter points, $150 \mathrm{~km}$ for Phalaborwa abattoir, $200 \mathrm{~km}$ for Thabazimbi abattoir and up to $400 \mathrm{~km}$ for Bronkhorstspruit abattoir (Figures 2a and 2b; Mokoele et al. 2014). The preferred means of transportation includes own vehicle (34.5\%), hired vehicle $(5.4 \%)$, shared vehicle $(1.4 \%)$ and other means $(58.8 \%, n=148)$.

\section{Social network analyses}

Using the in-going (in-degree) and out-going (out-degree) movement to and from the vertices, the most important nodes for disease spread are locations (Phalaborwa, Tzaneen, Belfast auction, Bronkhorstspruit abattoir, Elias Motsoaledi, Molemole), pension points or local markets, Tubatse, local slaughter points and Polokwane in that order (Figures 2a and $2 b, 4-7)$. Phalaborwa also has the highest degree of centrality whereas the top ten vertices ranked by $\mathrm{BC}$ were the local 


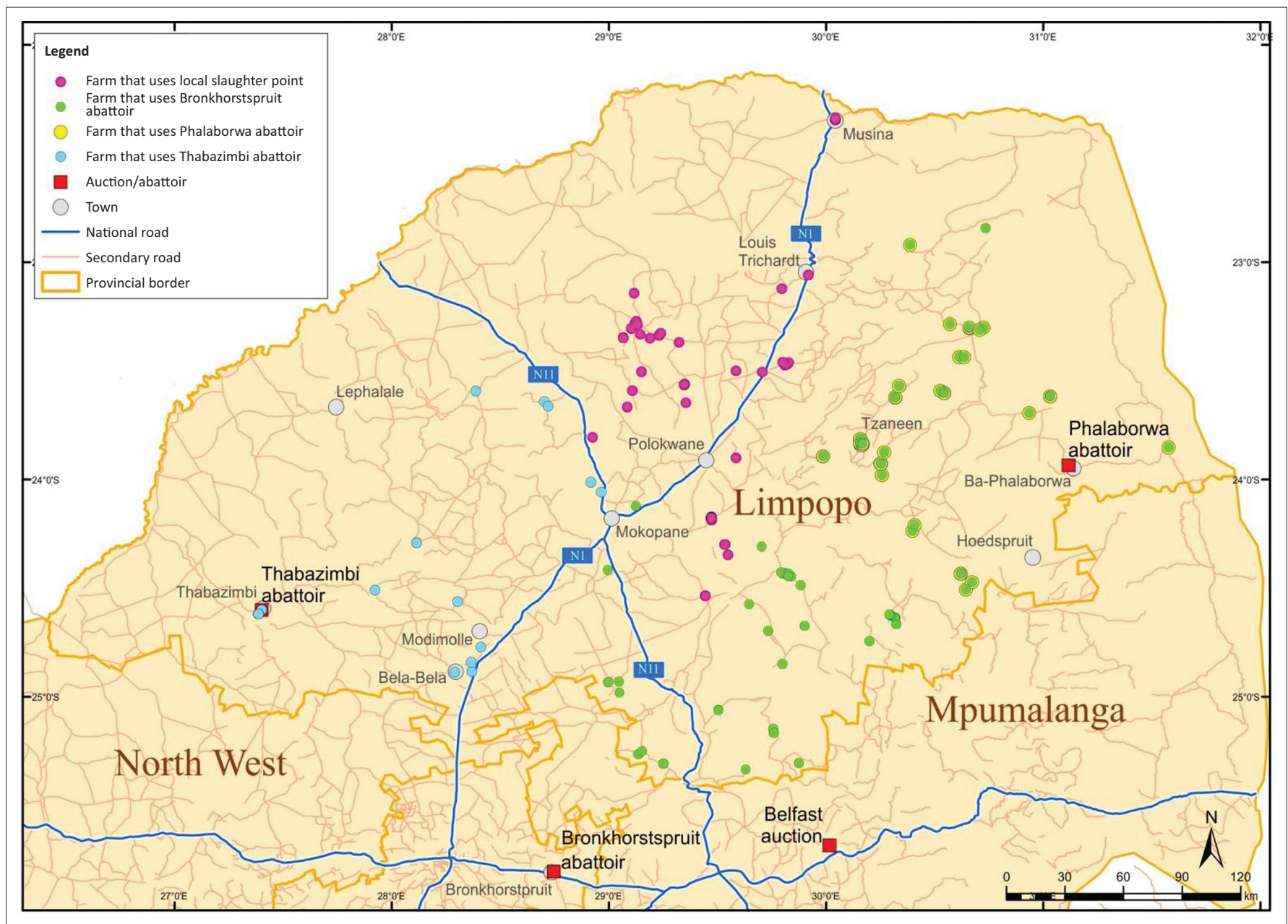

Source: Yvette Bevis and Ingrid Booysen, Geography, Geoinformatics and Meteorology, University of Pretoria

FIGURE 3: Distribution of locations of surveyed farms based on preferred slaughter location/auction markets and the national and secondary road networks.

TABLE 2: Preferred point of sale for pigs and pig products and the distances to the nearest national or secondary roads.

\begin{tabular}{|c|c|c|c|c|c|c|c|c|c|c|}
\hline \multirow[t]{2}{*}{ Preferred sale point } & \multirow{2}{*}{$\begin{array}{l}\text { Mean distance to } \\
\text { secondary road } \\
(\mathrm{km})\end{array}$} & \multicolumn{2}{|c|}{ Quartile (km) } & \multicolumn{2}{|c|}{ Range } & \multirow{2}{*}{$\begin{array}{l}\text { Mean distance } \\
\text { to national } \\
\text { road }(\mathrm{km})\end{array}$} & \multicolumn{2}{|c|}{ Quartile (km) } & \multicolumn{2}{|c|}{ Range } \\
\hline & & Lower (25th) & Upper (75th) & Minimum & Maximum & & Lower (25th) & Upper (75th) & Minimum & Maximum \\
\hline $\begin{array}{l}\text { Pension points and } \\
\text { local slaughter }(n=55)\end{array}$ & $1.624 \pm 1.859$ & 0.345 & 2.080 & 0.046 & 2.127 & $29.727 \pm 18.260$ & 10.896 & 42.394 & 0.193 & 65.702 \\
\hline $\begin{array}{l}\text { Bronkhorstspruit } \\
(n=88)\end{array}$ & $3.092 \pm 3.697$ & 0.481 & 4.120 & 0.035 & 13.962 & $74.386 \pm 38.686$ & 49.919 & 98.638 & 2.676 & 77.242 \\
\hline Phalaborwa $(n=43)$ & $4.728 \pm 4.484$ & 0.358 & 9.007 & 0.075 & 13.962 & $92.253 \pm 30.956$ & 69.280 & 112.454 & 49.919 & 201.289 \\
\hline Thabazimbi $(n=17)$ & $1.434 \pm 2.148$ & 0.155 & 1.450 & 0.005 & 7.713 & $45.895 \pm 46.169$ & 5.540 & 67.577 & 1.211 & 116.209 \\
\hline
\end{tabular}

Source: Yvette Bevis and Ingrid Booysen, Geography, Geoinformatics and Meteorology, University of Pretoria

Note: The smaller map indicates Limpopo with contiguous provinces of North West, Gauteng and Mpumalanga, and some other provinces (northern Cape, Free State and KwaZulu-Natal). The call-out map clearly indicates the districts within Limpopo and the spread of the sampled sites.

slaughter points, Phalaborwa, Thabazimbi, Bronkhorstspruit, Molemole, Ephraim Mogale, Letaba, Tzaneen, Makhado and Blouberg (see Figure 5 and Online Appendix 2).

Overall, the unidirectional graph has 28 vertices and 2 unique edges with a total of 161 edges. There were 4 connected components with an average geodesic distance (shortest path between points) of 1.48. The graph density (a function of the edges and vertices that make up a network) had a value of 0.06 and an average clustering coefficient (a measure of the degree to which nodes cluster together within the network) of 0.000 (Online Appendix 2).

\section{Discussion}

This study revealed that informal pig movements and trade networks in Limpopo exist. While we did not investigate the specific role of each farmer and the middlemen, we confirmed that trade-associated short and long-distance movements of pigs and pig products exist within the province $(5 \mathrm{~km}-400 \mathrm{~km})$. 


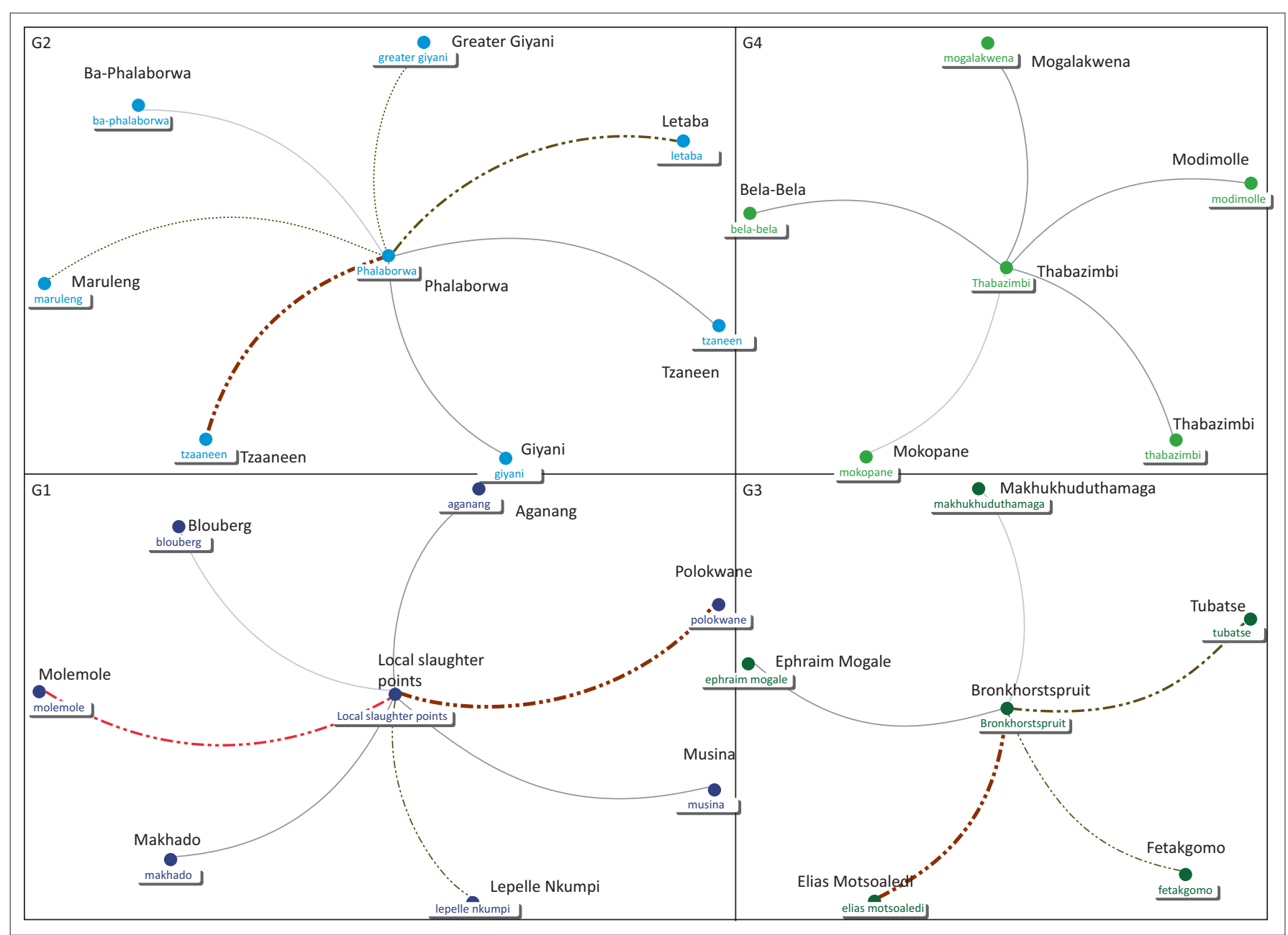

Source: Marc A. Smith, Connected Action Consulting Group

Note: The slaughtering points (local, Phalaborwa, Bronkhorstspruit and Thabazimbi) appeared to have the greatest influences on disease dispersal. Following infections through contacts networks, these points will rapidly serve to disperse new infections. The edge colours, edge widths and edge opacities are based on edge weight values. The vertex sizes are based on betweenness centrality values (see Online Appendix 1 for raw values).

FIGURE 4: Network map of connected locations for emerging small-scale pig farmers in Limpopo.

Monthly, up to 306 pigs may be transported individually or collectively in shared facilities over a short or long distance to major abattoirs or auction points and these transports may facilitate long-distance risk of disease dispersal. In a case of a rapidly spreading disease outbreak, trade by these farmers could facilitate the rapid spread of disease across broad geographic areas as was the case of the Lephalale-SundraRietpoort (Limpopo-Mpumalanga-Gauteng) African swine fever outbreak of 2011-2012. It will be necessary to target the ESSPFs and associated downstream sector traders in this sector for animal health and biosecurity training. In addition, animal health intervention and prevention strategies should target these ESSPF (McCarron et al. 2015). Previous reports have confirmed that the majority of the past outbreaks of ASF have involved ESSPF from Limpopo (DAFF 2014).

Several important nodes (towns and cities) with high levels of interactions and the potential to contribute to or rapidly spread pig pathogens inadvertently were identified. These nodes acted as dispersal and sometimes collection points. Phalaborwa, Thabazimbi, Bronkhorstspruit and Belfast are among such important points and there is a need to create surveillance points and inspection nodes around these locations. The first two locations are within Limpopo but the last two are located in the adjacent Gauteng and Mpumalanga, where higher market values are the main drivers for the ESSPFs travelling these distances. It will be important to improve pig marketing locally and add value to pork products in Limpopo to discourage long-distance travel, because such trips can pose a risk of spread of infection outside the control area. Although a movement control policy is implemented in South Africa, which includes a prohibition of the movement of pigs out of the ASF control area without a veterinary permit only issued under specified conditions, emergency situations and economic imperatives often challenge such policies. There is therefore a need for enhanced vigilance on the part of the authorities, including active surveillance and participatory epidemiology among the ESSPFs.

In addition, there is a need to motivate ESSPF to apply good farming practice with improved biosecurity, which will be rewarded by access to a scaled-up pricing system for pork certified by local veterinarians through a government support system (Fasina et al. 2010, 2012b; Logar 2014). 


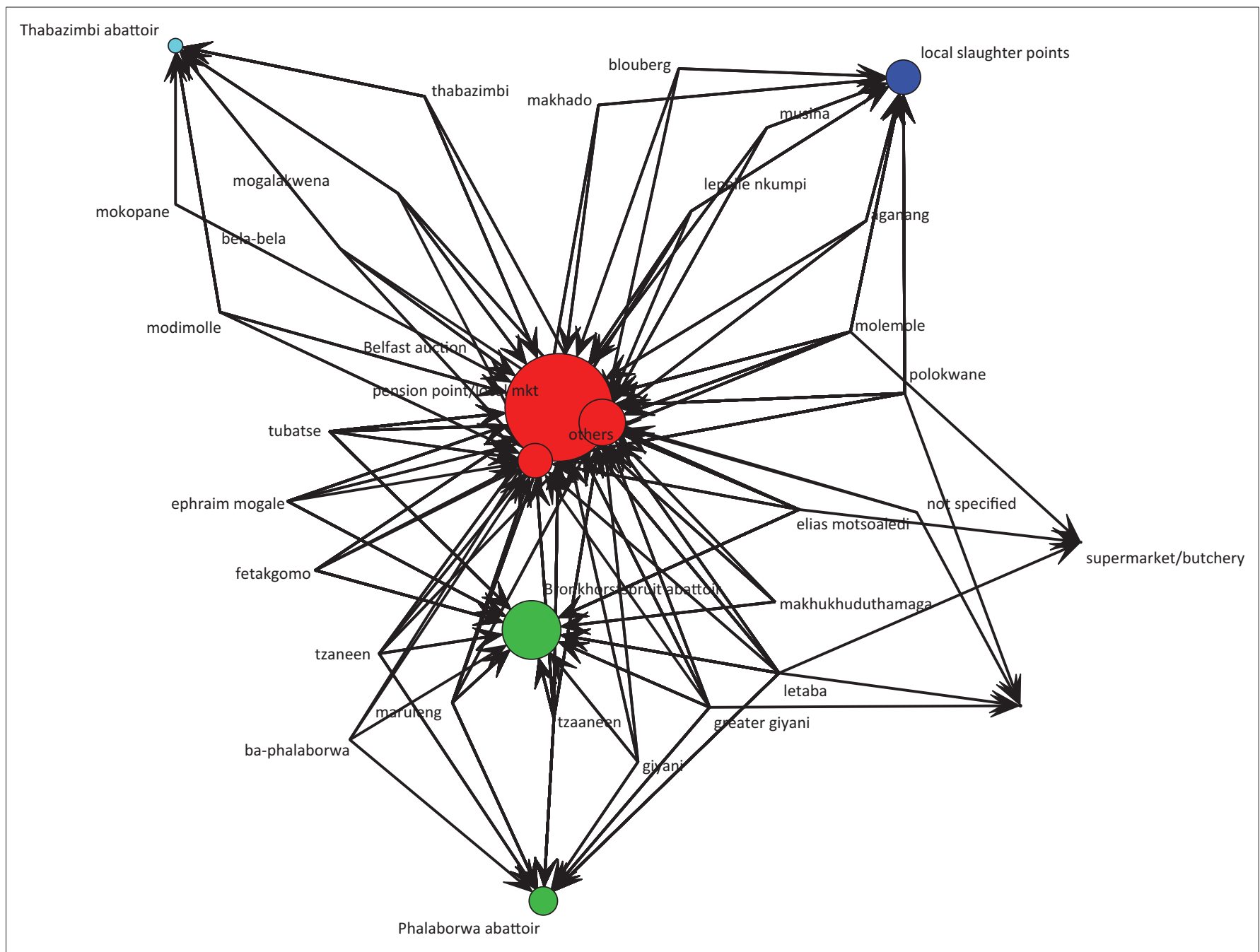

Source: Eric Etter, CIRAD and Production Animal Studies, University of Pretoria

Note: Figure 5 showed all the possible interconnectedness of all locations surveyed: A total of 554 connections.

FIGURE 5: Multidirectional network map of in-degree connectedness of locations of emerging small-scale pig farmers in Limpopo, 2012.

Since local slaughter and pension point sales were also revealed as important trade nodes, these activities may conceal the existence of subclinical infections and prevent early detection of rapidly spreading transboundary animal diseases. Limpopo is of major interest because the great majority of ASF outbreaks over decades have occurred or originated there. It is an important disease node not only for ASF but potentially for other pig diseases.

While the movement of pigs between farms was not evaluated in this study, we are aware that such movements exist (Mokoele et al. 2014). Social networks associated with pig farms are important factors in the transmission of infectious diseases (Leslie et al. 2015). Our model has identified local slaughter points and other abattoirs as potentially having the greatest influence on disease dispersal. Strict anticipatory planning should be implemented in these locations and controlled slaughter should be encouraged (Kao et al. 2007; Lindström et al. 2010).

Our evaluation and analyses are based on certain assumptions. First, we assumed that the records are complete and the data used in the evaluations are accurate; it is important for recording officials to pay particular attention to data entry in the future, as critical analysis based on available data may be warranted. We have made every effort to verify the data and confirm certain facts where there are doubts; secondly, we did not discriminate between respondents, partial respondents and non-respondents as we eliminated all partially filledin questionnaires. This resulted in differing denominators and may sometimes hide some important answers. Some degree of recall bias may have occurred with regard to certain questions that made reference to the past years. Moreover, since only the surveyed farmers were included in the networks, it is possible that some other smallholder pig farmers exist whose inclusion may significantly influence and change the strengths and directions of the networks. Thirdly, the social network analytic method used in this study has certain limitations including the following:

- An assumption that all disease algorithms often exhibit 'small world' properties in a situation of close interconnectedness in temporal and spatial locality (Jiang et al. 2009); in the real world this may not always be true. 


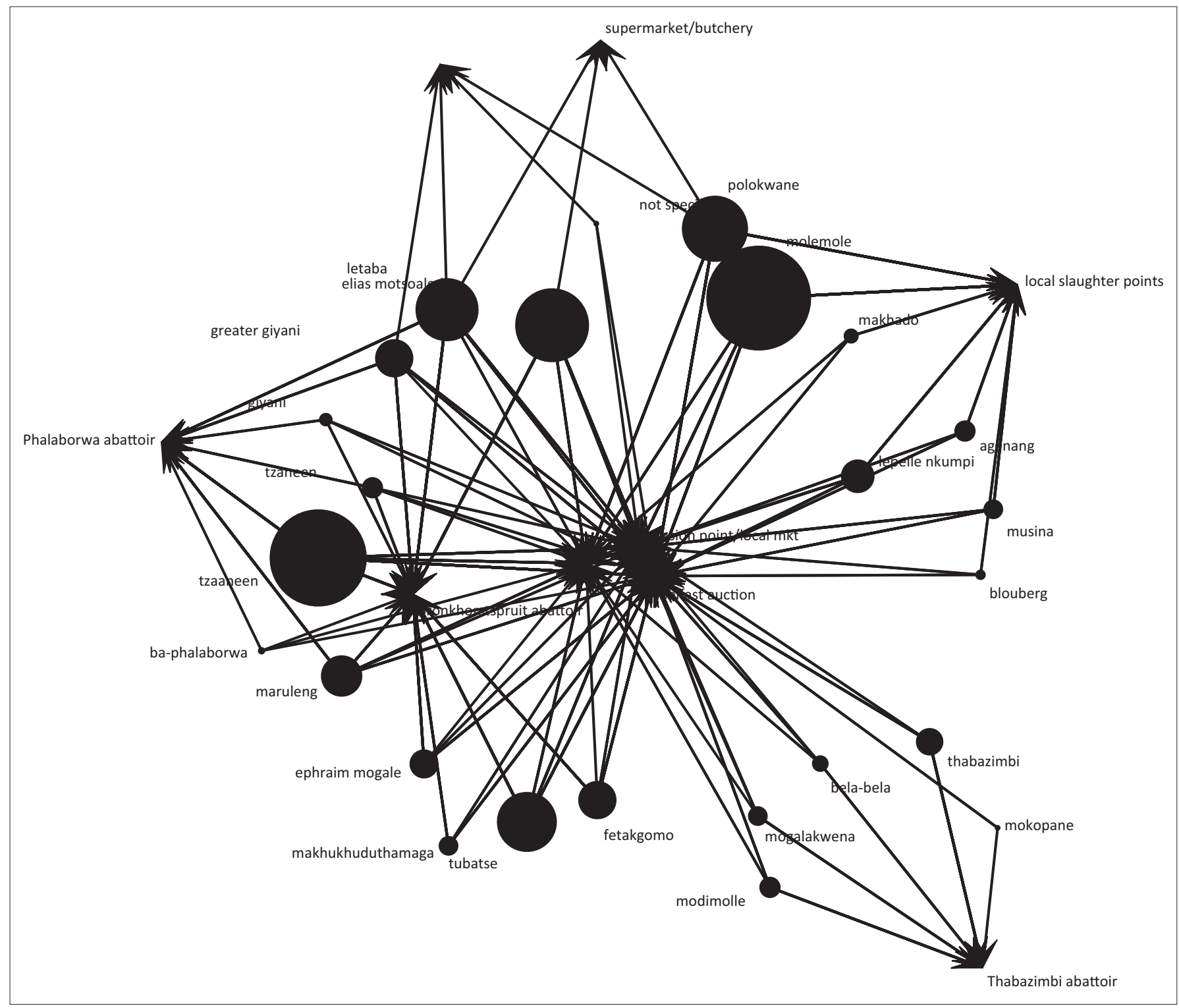

Source: Eric Etter, CIRAD and Production Animal Studies, University of Pretoria

FIGURE 6: Multidirectional network map of out-degree connectedness of locations of emerging small-scale pig farmers in Limpopo, 2012.

- An assumption that an analysis kernel of BC can resolve all complexities of interconnectedness by measuring the shortest distances passing through vertices (Freeman 1977).

- The networks can sometimes identify false positive edges and false negatives especially where background noises are high in the dataset (Ufimtsev \& Bhowmick 2013). False positives may arise when two vertices have low to medium BC scores, which can combine to produce one with a high $\mathrm{BC}$ score. We have reduced this by creating four different networks for each identified node.

- Finally, the threshold in a given group testing may be affected by the false positive $\mathrm{BC}$ values. We have corrected for this influence in the course of the modelling.

In conclusion, we have produced evidence that geographic factors and trade-movement networks played roles in ASF dynamics and dispersal in South Africa and that managing these in Limpopo province is critical for pig disease control.
The degree of interconnectedness of the ESSPF in the province may facilitate disease spread by people, trade, animal movements and also possible sharing of transport and farm equipment as has been describe elsewhere (Kao et al. 2007; Leslie et al. 2015). While we have made effort to integrate the dynamics of recent and historical outbreaks of ASF in South Africa geo-temporally, it will be worthwhile to re-evaluate the specifics of the Lephalale-Sundra-Rietpoort outbreak of 20112012 and determine quantitatively the potential implications of 'along-the-road networks', the effect of delayed response due to travel time to auction time and treatment using antibiotics. These may reveal important hidden evidence of disease dynamics in the pig industry in South Africa

\section{Acknowledgements}

We acknowledge the Limpopo Department of Agriculture as the provider of funds for this survey as part of a postgraduate programme through the Human Resource 


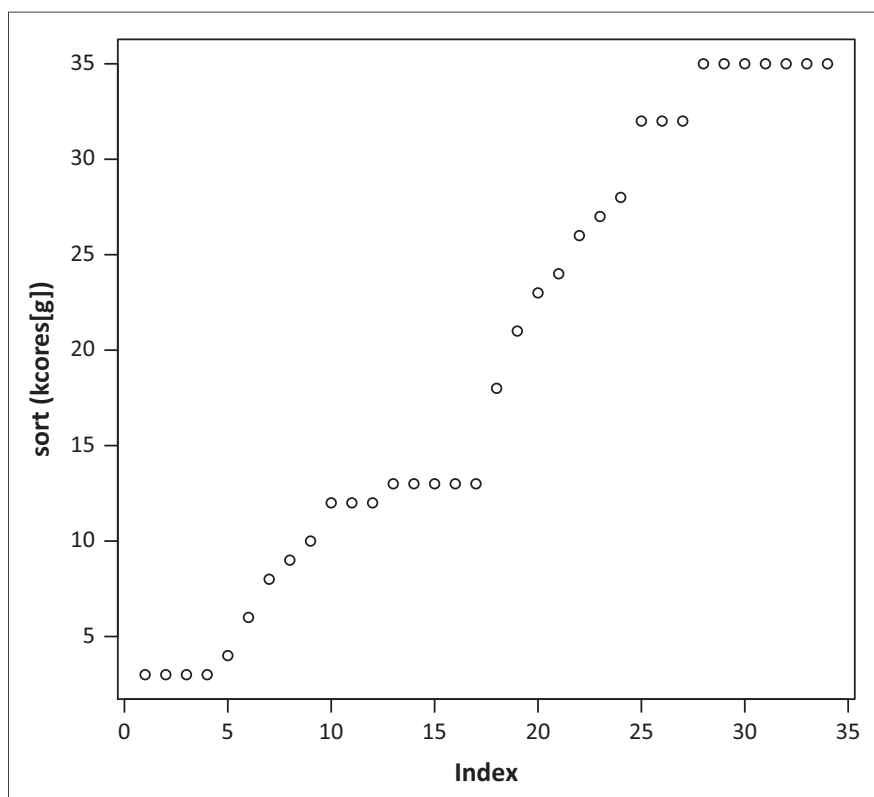

\begin{tabular}{|c|l|}
\hline K-cores & Locations \\
\hline 3 & Mokopane, supermarket/butchery, unspecified locations, unnamed locations \\
\hline 6 & Blouberg \\
\hline 8 & Giyani \\
\hline 9 & Makhado \\
\hline 10 & Bela-bela \\
\hline 12 & Makhukhuduthamaga, Mogalakwena, Musina \\
\hline 13 & Aganang, Modimolle \\
\hline 18 & Ephraim Mogale \\
\hline 21 & Lepelle Nkumpi \\
\hline 23 & Greater Giyani \\
\hline 24 & Fetakgomo \\
\hline 26 & Maruleng, Thabazimbi (Thabazimbi+Thabazimbi abattoir) \\
\hline 28 & Letaba \\
\hline 32 & Local slaughter points, Polokwane, other points \\
\hline 35 & $\begin{array}{l}\text { Belfast auction, Bronkhorstspruit abattoir, Elias Motsoaledi, Molemole, } \\
\text { Pension points/local markets, Tubatse }\end{array}$ \\
\hline 48 & Tzaneen (Tzaneen+Tzaaneen) \\
\hline 57 & Phalaborwa (Phalaborwa + Ba-Phalaborwa+ P. abattoir) \\
\hline
\end{tabular}

Source: Eric Etter, CIRAD and Production Animal Studies, University of Pretoria

Note: Figure 7 showed all the possible interconnectedness of all the locations surveyed. A total of 554 connections exist and some location influences the connections up to $10 \%$ (Phalaborwa) and the least connections.

FIGURE 7: Structural cohesion (k-core) of network map of connected locations of emerging small-scale pig farmers in Limpopo, 2012.

Development Section, the Director of Veterinary Services in Limpopo province, Dr Mampane, and his team of managers in the districts and all the veterinary officials for their help with the collection of data in their respective districts. The Department of Production Animal Studies and the Faculty of Veterinary Science, Onderstepoort partially supported this work with funding and resources. We thank Marc A. Smith and the team at Connected Action Consulting Group (http://www.connectedaction.net/) for assistance with SNA mapping. We gratefully acknowledge the input of Assoc. Prof. Eric Etter (University of Pretoria) for assistance with multidirectional SNA.

\section{Competing interests}

The authors declare that they have no financial or personal relationships which may have inappropriately influenced them in writing this article.

\section{Authors' contributions}

F.O.F. (University of Pretoria) and J.M.M. (University of Pretoria) designed the study. J.M.M. carried out the field survey. F.O.F. carried out the statistical analyses. B.T.S (University of Pretoria) and L.A.M.L.v.L. (University of Pretoria) supervised the project. Y.B. (University of Pretoria) and I.B. (University of Pretoria) drew the maps and contributed materials for the study. All the authors contributed to the writing and revision of the manuscript and its final approval. F.O.F. was the project coordinator.

\section{References}

Antwi, M. \& Seahlodi, P., 2011, 'Marketing constraints facing emerging small-scale pig farmers in Gauteng province', South Africa Journal of Human Ecology 36, 37-42.
Bastos, A.D.S., Fasina, F.O. \& King, D.P., 2014, 'African swine fever virus', in L. Dongyou (ed.), Manual of security sensitive microbes and toxins, pp. 579-587, CRC Press, New South Wales. e-book, from http://www.crcpress.com/product/ isbn/9781466553965.

Boshoff, C.I., Bastos, A.D.S., Gerber, L.J. \& Vosloo, W., 2007, 'Genetic characterisation of African swine fever viruses from outbreaks in Southern Africa (1973-1999)',
Veterinary Microbiology 121, 45-55. PMID: 17174485, http://dx.doi.org/10.1016/j. Veterinary Microbiology
vetmic.2006.11.007

De Glanville, W.A., Vial, L., Costard, S., Wieland, B. \& Pfeiffer, D.U., 2014, 'Spatia multi-criteria decision analysis to predict suitability for African swine multi-criteria decision analysis to predict suitability for African swine
fever endemicity in Africa', BMC Veterinary Research 10, 9. http://dx.doi. org/10.1186/1746-6148-10-9

De Kock, G., Robinson, E.M. \& Keppel, J.J.G., 1940, 'Swine fever in South Africa', Onderstepoort Journal of Veterinary Science and Animal Industry 14, 31-93.

Department of Agriculture, Fisheries and Forestry (DAFF), n.d., African swine fever control zone in South Africa, viewed 10 April 2014, from http://www.nda.agric.za/ vetweb/epidemiology/Disease\%20Maps/ASFcopy.pdf

Department of Agriculture, Forestry and Fisheries (DAFF), 2014, Data on African swine fever outbreaks in South Africa from Jan 1993 to April 2014, viewed 10 April 2014 from http://www.nda.agric.za/vetweb/epidemiology/Disease\%20Database/ OIEData/oie query.asp?cmbfromyear=1993\&cmbfrommonth=01\&cmbtoyear=2 $012 \& \mathrm{cmbtomonth}=01 \&$ sprovince $=\& \mathrm{~s}$ District $=\&$ sdisease $=A 120 \&$ sspecies $=$

Evans, P., 2012, 'African swine fever: Sundra outbreak update', Porcus, 06 April/May, p. 9.

Fasina, F.O., Agbaje, M., Ajani, F.L., Talabi, O.A., Lazarus, D.D., Gallardo, C. et al., 2012b, 'Risk factors for farm-level African swine fever infection in major pig-producing areas in Nigeria, 1997-2011', Preventive Veterinary Medicine 107, 65-75. PMID: 22717326, http://dx.doi.org/10.1016/j.prevetmed.2012.05.011

Fasina, F.O., Lazarus, D.D., Spencer, B.T., Makinde, A.A. \& Bastos, A.D.S., 2012a, 'Cost implications of African swine fever in smallholder farrow-to-finish units: Economic benefits of disease prevention through biosecurity', Transboundary and Emerging Diseases 59, 244-255. PMID: 21929615, http://dx.doi.org/10.1111/j.1865Diseases 59, 244-25

Fasina, F.O., Shamaki, D. Makinde, A.A., Lombin L.H., Lazarus, D.D., Rufai, S.A. et al. 2010, 'Surveillance for African swine fever in Nigeria, 2006-2009', Transboundary and Emerging Diseases 57, 244-253. PMID: 20561290, http://dx.doi.org/10.1111/ and Emerging Diseases 57,

Food and Agriculture Organisation of the United Nations (FAO), 2013, 'African swine fever in the Russian Federation: Risk factors for Europe and beyond' EMPRES Watch, vol. 28, May 2013, viewed 27 April 2014, from www.fao.org/ag/empres. Watch,
html

Fournié, G., Guitian, J., Desvaux, S., Cuong, V.C., Dung, D.H., Pfeiffer, D.U. et al., 2013 , 'Interventions for avian influenza A (H5N1) risk management in live bird market networks', Proceedings of the National Academy of Science of the United States of America 110(22), 9177-9182. http://dx.doi.org/10.1073/pnas.1220815110

Freeman, L.C., 1977, 'A set of measures of centrality based on betweenness', Sociometry 40, 35-41. http://dx.doi.org/10.2307/3033543

Jiang, K., Ediger, D. \& Bader, D.A., 2009, 'Generalising k-betweenness centrality using short paths and a parallel multithreaded implementation', Proceedings of the International Conference on Parallel Processing, Vienna, Austria, September 
22-25, 2009, viewed 27 July 2015, http://doi.ieeecomputersociety.org/10.1109/ ICPP. 2009.76

Jones, B.A., Grace, D., Kock, R., Alonso, S., Rushton, J., Said, M.Y. et al., 2013, 'Zoonotic emergence linked to agricultural intensification and environmental change', Proceedings of the National Academy of Science of the United States of America 110(21), 8399-8404. http://dx.doi.org/10.1073/pnas.1208059110

Jori, F., Vosloo, W., du Plessis, B., Bengis, R., Brahmbhatt, D., Gummow, B. et al., 2009, 'A qualitative risk assessment of factors contributing to foot and mouth disease outbreaks in cattle along the western boundary of the Kruger National Park', Revue Scientifique et Technique, Office international des Épizooties 28(3) 917-931. PMID: 20462150

Kao, R.R., Green, D.M., Johnson, J. \& Kiss, I.Z., 2007, 'Disease dynamics over very different time-scales: Foot-and-mouth disease and scrapie on the network of livestock movements in the UK', Journal of the Royal Society Interface 4, 907-916. http://dx.doi.org/10.1098/rsif.2007.1129

Korennoy, F.I., Gulenkin, V.M., Malone, J.B., Mores, C.N., Dudnikov, S.A. \& Stevenson, M.A., 2014, 'Spatio-temporal modeling of the African swine fever epidemic in the Russian Federation, 2007-2012', Spatial and Spatio-temporal Epidemiology 11 135-141. http://dx.doi.org/10.1016/j.sste.2014.04.002

Leslie, E.E.C., Christley, R.M., Geong, M., Ward, M.P. \& Toribio, J.-A.L.M.L., 2015 'Analysis of pig movements across eastern Indonesia, 2009-2010', Preventive Veterinary Medicine 118, 293-305. PMID: 25534972, http://dx.doi.org/10.1016/j. prevetmed.2014.12.002

Lindström, T., Sisson, S.A., Lewerin, S.S. \& Wennergren, U., 2010, 'Estimating animal movement contacts between holdings of different production types', Preventive Veterinary Medicine 95, 23-31. PMID: 20356640, http://dx.doi.org/10.1016/j. prevetmed.2010.03.002

Lindström, T., Sisson, S.A., Nöremark, M., Jonsson, A. \& Wennergren, U., 2009 'Estimation of distance related probability of animal movements between holdings 'Estimation of distance related probability of animal movements between holdings and implications for disease spread modeling', Preventive Veterinary Medicine 91 , PMID: 19540009, http://dx.doi.org/10.1016/j.prevetmed.2009.05.022

Logar, B., 2014, 'Future EU animal health regulation: A step forward to a better biosecurity', A presentation at the Nordic-Baltic Veterinary Contingency
Group 'Biosecurity, Experiences, Training, Motivation and Economic aspects',

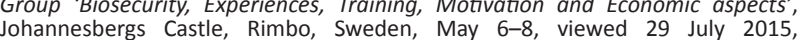
Johannesbergs Castle, Rimbo, Sweden, May 6-8, viewed 29 July 2015,
from http://www.jordbruksverket.se/download/18.37e9ac46144f41921cd from http://www.jordbruksverket.se/download/1
eb57/1399627544437/l+2,+Barbara+Logar,+KOM.pdf

Martínez-López, B., Pérez, A.M. \& Sánchez-Vizcaíno, J.M., 2009, 'Combined application of social network and cluster detection analyses for temporalspatial characterization of animal movements in Salamanca, Spain', Preventive Veterinary Medicine 91, 29-38. PMID: 19500865, http://dx.doi.org/10.1016/j. Veterinary Medicine 91,
prevetmed.2009.05.007

McCarron, M. Munyua, P.M Cheng, P.-Y, Manga, T., Wanjohid, C., Moen, A. et al., 2015, 'Understanding the poultry trade network in Kenya: Implications for regional disease prevention and control', Preventive Veterinary Medicine 120, 321-327. PMID: 26002998, http://dx.doi.org/10.1016/ Medicine $120,321-327$
j.prevetmed.2015.03.021

Mokoele, J.M., Spencer, B.T., van Leengoed, L.A.M.G. \& Fasina, F.O., 2014, 'Efficiency indices and indicators of poor performance among emerging small scale pig farmers, Limpopo, South Africa', Onderstepoort Journal of Veterinary Research 81(1), Art. \#774, 12 pages PMID: 25685963, http://dx.doi.org/10.4102/ojvr. v81i1.774

Nøremark, M. \& Widgren, S., 2015, 'Epidemiological tool for contact tracing (Package "EpiContactTrace")', viewed 16 June 2015, from http://cran.r-project.org/web/ packages/EpiContactTrace/EpiContactTrace.pdf.

Pastrana, M.E.O., Brito, R.L., Nicolino, R.R., de Oliveira, C.S.F. \& Haddad, J.P.A., 2014 'Spatial and statistical methodologies to determine the distribution of dengue in Brazilian municipalities and relate incidence with the health vulnerability index', Spatial and Spatio-temporal Epidemiology 11, 143-151. http://dx.doi. org/10.1016/j.sste.2014.04.001

Paul, S. \& Dasgupta, A., 2012, 'Spatio-temporal analysis to quantify urban sprawl using geoinformatics', International Journal of Advances in Remote Sensing and GIS 1 234-248.

Penrith, M.-L., 2013, 'History of "swine fever" in Southern Africa', Journal of the South African Veterinary Association 84(1), Art. \#1106, 6 pages. http://dx.doi org/10.4102/jsava.v84i1.1106

Penrith, M.-L., Thomson, G.R. \& Bastos, A.D.S., 2004, 'African swine fever', in J.A.W. Coetzer \& R.C. Tustin (eds.), Infectious diseases of livestock, 2nd edn., vol. 2, pp. 1088-1119, Oxford University Press, Cape Town.

Penrith, M.-L. \& Vosloo, W., 2009, 'Review of African swine fever: Transmission, spread and control', Journal of the South African Veterinary Association 80(2), 58-62. PMID: 19831264, http://dx.doi.org/10.4102/jsava.v80i2.172

Perry, B.D., Grace, D. \& Sones, K., 2013, 'Current drivers and future directions of global livestock disease dynamics', Proceedings of the National Academy of Science of the United States of America 110(52), 20871-20877. http://dx.doi.org/10.1073/ the United States

Raman, K.V., Sanghi, N.K. \& Chambers, R., 1989, 'Part 2: Institutions and practical change', in R. Chambers, A. Pacey \& L.A. Thrupp (eds.), Farmer first: Farmer innovation and agricultural research, pp. 55-105, IT Publications, London.

Rivas, A.L., Chowell, G., Schwager, S.J., Fasina, F.O., Hoogesteijn, A.L., Smith, S.D. et al., 2010, 'Lessons from Nigeria: The role of roads in the geo-temporal progression of the avian influenza (H5N1)', Epidemiology and Infection 138, 192-198. PMID: 19653927, http://dx.doi.org/10.1017/S0950268809990495

Rivas, A.L., Fasina, F.O., Hoogesteyn, A.L., Konah, S.N., Febles, J.L., Perkins, D.J. et al., 2012, 'Connecting network properties of rapidly disseminating epizootics', PLoS ONE 7(6), e39778. http://dx.doi.org/10.1371/journal.pone.0039778

Sánchez-Vizcaíno, J.M., Mur, L. \& Martínez-López, B., 2012, 'African swine fever: An epidemiological update', Transboundary and Emerging Diseases 59(s1), 27-35.

Spencer, B.T., 2012, 'Rapid control of an "abnormal" outbreak of African swine fever outside the controlled ASF area', Article EO-222, Proceedings of the 22nd International Pig Veterinary Society Congress, Jeju, Korea, June 10-13, p. 296

Spencer, T. \& Penrith, M.-L., 2014, 'The South African way of dealing with ASF', Pig Progress 30(3), 1445.

Ufimtsev, V. \& Bhowmick, S., 2013, 'Application of group testing in identifying high betweenness centrality vertices in complex networks', Eleventh Workshop on
Mining and Learning with Graphs, Chicago, IL, viewed 03 June 2014, from http:// snap.stanford.edu/mlg2013/submissions/mlg2013 submission_3.pdf 